\title{
Methods for Selection of Mutants and In Vitro Culture of Cochliobolus heterostrophus
}

\author{
By J. LEACH, B. R. LANG AND O. C. YODER* \\ Department of Plant Pathology, Cornell University, Ithaca, New York 14853, U.S.A.
}

(Received 17 November 1981; revised 7 January 1982)

\begin{abstract}
Auxotrophic, morphological and drug-resistant mutants of Cochliobolus heterostrophus (= Bipolaris maydis = Helminthosporium maydis = Drechslera maydis) were isolated after mutagenesis with ethyl methanesulphonate. Exposure of the fungus to other mutagens ( $N$-methyl- $N^{\prime}$-nitro- $N$-nitrosoguanidine, nitrous acid, and UV light) resulted in recovery of morphological but not auxotrophic mutants. Antibiotic enrichment or filtration enrichment in medium containing high levels of sorbose increased the proportion of auxotrophs in the surviving population. All sexually fertile mutants were found to have single gene lesions; those with the same phenotype were allelic in some cases but not in others. Defined minimal and complete media, designed to facilitate genetic and molecular biological manipulations, supported maximal growth rate at $30^{\circ} \mathrm{C}$ and maximal conidiation of the fungus at $23^{\circ} \mathrm{C}$ with a $16 \mathrm{~h}$ long-wave UV light photoperiod. Under all in vitro growth conditions tested, near-isogenic lines of two known races of the fungus were essentially identical. Sexual fertility was improved by a programme of breeding and selection, but not by physical or chemical changes in the medium used for crossing. The fungus can be stored conveniently on silica gel.
\end{abstract}

\section{INTRODUCTION}

Cochliobolus heterostrophus Drechsler [anamorphic names: Bipolaris maydis (Nisik.) Shoemaker, Helminthosporium maydis Nisik., Drechslera maydis (Nisik.) Subram. and Jain], the causal agent of southern corn leaf blight, has been selected as a model eukaryotic plant pathogen for analysing molecular mechanisms of pathogenicity. This host-parasite combination has the following favourable characteristics. (1) Both the sexual and asexual stages of the parasite can be manipulated in vitro (Yoder \& Gracen, 1975). (2) The fungus has a single locus with two alleles that control two levels of virulence; the alleles can be readily distinguished in vitro because one of them controls production of a secondary metabolite (HMT-toxin) that is required for high virulence (Yoder \& Gracen, 1975). (3) The genetics of the host plant, corn (Zea mays L.), is well understood; resistance of corn to $C$. heterostrophus is controlled by both nuclear and cytoplasmic genes (Payne \& Yoder, 1978). (4) Quantitative epidemiological assays are available to assess the effects of specific genes on disease development under field conditions (Garber et al., 1981).

Genetic manipulation of the pathogen is essential for rigorous biochemical analysis of disease initiation and development. Effective manipulation requires methods for selection of auxotrophic and drug resistant mutants and for genetic recombination. Yet organisms as they are recovered from nature are usually difficult to handle in culture and special methods for in vitro manipulation and conditions for culture must be established for each 'experimentally undomesticated' organism (Lindegren et al., 1939; Lindegren \& Lindegren, 1944; Srb, 1974; Bassel \& Ogrydziak, 1979). This paper reports mutagenesis and selection procedures that are effective with $C$. heterostrophus, as well as cultural conditions for efficient laboratory manipulation and maintenance. 


\section{METHODS}

Strains. Two single-ascospore isolates of $C$. heterostrophus were obtained after six back-cross generations to a recurrent parent. Isolate $\mathrm{C} 2$ (ascospore number 110-1-2) was albino (alb1), mating type $\mathrm{A}$ (mat A), and had the allele for production of HMT-toxin (tox+). Isolate C3 (ascospore number 117-6-6) was pigmented, mating type a (mata), and had the alternative allele, for no HMT-toxin production (tox-). The recurrent parent isolate $\mathrm{C1}$ (ascospore number 75-4-4) was pigmented, matA, tox+. Its progenitors (Fig. 1) were all tox+. Isolates NY9 matA and NY338 mata were collected in New York State in 1970 and 1971, respectively, whereas isolates NC92 alb 1; mata and NC80 mata were obtained from K. J. Leonard and were isolated in North Carolina in 1970 (alb 1 is a spontaneous mutant of NC92). Isolate C4 (ascospore number 141-2-1) was pigmented, mata and tox+. It was the product of a cross between $\mathrm{C} 2$ and C3. The strains were chosen for uniform morphology and olivaceous pigmentation (except for alb1), sexual fertility, and ability to form typical lesions on a standard set of corn differentials (Yoder, 1976). To avoid the variation that develops during repeated vegetative transfers, isolates were retrieved fresh from storage before each experiment.

Media. Potato juice agar (PJA) was prepared as potato dextrose agar without added dextrose (Yoder \& Gracen, 1975). Minimal medium (MM) contained $10 \mathrm{ml}$ of each of two $100 \times$ salts solutions (solutions A and B), $1.0 \mathrm{ml}$ of micronutrient stock solution (Sanderson \& Srb, 1965), $10 \mathrm{~g}$ glucose, $20 \mathrm{~g}$ agar, and deionized water to 1 litre. Portions of $18 \mathrm{ml}$ of agar medium were used in $10 \mathrm{~cm}$ diameter plastic Petri dishes. Stock salt solution A contained $10 \mathrm{~g} \mathrm{Ca}\left(\mathrm{NO}_{3}\right)_{2} .4 \mathrm{H}_{2} \mathrm{O}$ and deionized water to $100 \mathrm{ml}$. Stock salt solution B contained $2.0 \mathrm{~g} \mathrm{KH}_{2} \mathrm{PO}_{4}, 2.5 \mathrm{~g}$ $\mathrm{MgSO}_{4} \cdot 7 \mathrm{H}_{2} \mathrm{O}, 1.5 \mathrm{~g} \mathrm{NaCl}$ and deionized water to $100 \mathrm{ml}$ (pH 5.3). Complete medium (CM) was MM plus $1 \mathrm{~g}$ yeast extract, $0.5 \mathrm{~g}$ acid-hydrolysed casein and $0.5 \mathrm{~g}$ enzymically hydrolysed casein, per litre. To induce colonial growth for plating, the glucose concentration of $\mathrm{CM}$ and $\mathrm{MM}$ was reduced $\left(0.5 \mathrm{gl}^{-1}\right.$ in $\mathrm{CM}$ or $2.0 \mathrm{gl}^{-1}$ in $\mathrm{MM}^{-}$ and sorbose $\left(20 \mathrm{~g}^{-1}\right)$ was added.

Growth measurements. Growth was measured by taking the average of the diameters (measured at right angles to each other) of each colony grown for $7 \mathrm{~d}$ on agar medium in a $10 \mathrm{~cm}$ diameter Petri dish which had been inoculated with a $3 \mathrm{~mm}$ diameter mycelial plug taken from the margin of a $2 \mathrm{~d}$ old culture on CM. Conidiation was measured either by estimating numbers microscopically, or by suspending the conidia produced in two $10 \mathrm{~cm}$ diameter Petri dishes of agar medium in water containing two drops of Tween 20 (polysorbitan monolaurate) per $100 \mathrm{ml}$, and counting them in a haemocytometer.

Mutagenesis procedures. Conidia from cultures of isolate $\mathrm{C} 2$ grown for $9-14 \mathrm{~d}$ on $\mathrm{CM}$ at $23^{\circ} \mathrm{C}$ with $16 \mathrm{~h}$ light,

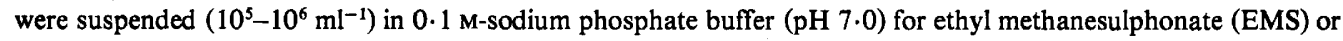
$N$-methyl- $N^{\prime}$-nitro- $N$-nitrosoguanidine (NTG) mutagenesis, in $0.1 \mathrm{M}$-sodium acetate $(\mathrm{pH} 4.4)$ for nitrous acid mutagenesis, or in water for UV light mutagenesis. All solutions contained 2 drops of Tween 20 per 100 ml. Final concentrations of EMS, NTG, and nitrous acid were $6 \%(\mathrm{v} / \mathrm{v}), 200 \mu \mathrm{M}$, and $4 \mathrm{mM}$, respectively; the UV dose (Sylvania germicidal G15T8 tubes) was $18 \mu \mathrm{J} \mathrm{s}^{-1} \mathrm{~mm}^{-2}$. Exposure times, adjusted to give about $1 \%$ survival, were $90 \mathrm{~min}$ for EMS, $5.5 \mathrm{~h}$ for NTG, $50 \mathrm{~min}$ for nitrous acid and $3 \mathrm{~min}$ for UV light. For chemical mutagenesis, suspensions were incubated at $24^{\circ} \mathrm{C}$ on a rotary shaker $\left(100 \mathrm{rev} . \mathrm{min}^{-1}\right)$. Mutagenesis was stopped by adding an equal volume of sodium thiosulphate $(8 \%, w / v)$ to EMS, two volumes of buffer to NTG, or four volumes of buffer ( $\mathrm{pH} \mathrm{7.0)}$ to nitrous acid. Conidia were concentrated by centrifugation of the conidial suspension, washed, resuspended in water, and either plated directly on to $\mathrm{CM}$ plus sorbose or subjected to an enrichment procedure before plating.

Enrichment for auxotrophs. Nystatin $\left(10 \mu \mathrm{g} \mathrm{ml}^{-1}\right)$ and cycloheximide $\left(100 \mu \mathrm{g} \mathrm{ml}^{-1}\right)$ were used to eliminate prototrophs, using the general procedure of Snow (1966). Mutagenized conidia were incubated in liquid MM ( $200 \mathrm{ml}$ per $500 \mathrm{ml}$ flask) at $24^{\circ} \mathrm{C}$ on a rotary shaker $\left(100 \mathrm{rev} . \mathrm{min}^{-1}\right)$ for $16-24 \mathrm{~h}$. Antibiotic was added and incubation continued for $2 \mathrm{~h}$ with nystatin or $48 \mathrm{~h}$ with cycloheximide. Conidia were collected by centrifugation, resuspended in water, and plated on CM plus sorbose. For filtration enrichment (Woodward et al., 1954), conidia were incubated in liquid $\mathrm{MM}$ for $3 \mathrm{~d}$; every $8 \mathrm{~h}$ the suspension was filtered through four layers of cheesecloth. After nine filtrations conidia were collected by centrifugation and plated on CM plus sorbose. For high sorbose filtration enrichment (Applegate et al., 1978; Yoder, 1979) MM salts were supplemented with $0.2 \%$ (w/v) glucose and $2.0 \%(\mathrm{w} / \mathrm{v})$ sorbose, filtration being at $24 \mathrm{~h}$ intervals. Conidia for the 'inositol-less death' procedure (Lester \& Gross, 1959) were produced by growing inositol-requiring auxotrophs on MM containing $20 \mathrm{mg}$ inositol $\mathrm{1}^{-1}$. They were mutagenized with EMS and plated on MM. After $24-36 \mathrm{~h}$, the plates were overlaid with CM plus sorbose containing $1 \%(\mathrm{w} / \mathrm{v})$ agar and $20 \mathrm{mg}$ inositol $\mathrm{1}^{-1}$. Resulting colonies were assayed for double auxotrophy.

Characterization of mutants. Colonies arising on CM after enrichment for auxotrophs were transferred to MM. Those that failed to grow on MM, plus all drug resistant or morphological mutants, were mated with isolate C3; progeny tests were done to ascertain the genetic control of each mutation. Specific nutritional requirements were determined by the methods of Holliday (1956). Independently arising auxotrophs with the same requirements were tested for allelism by heterokaryotic complementation. Agar blocks $(2 \times 2 \times 2 \mathrm{~mm})$ bearing mycelium of each isolate were placed together on $\mathrm{MM}$, each isolate also being plated alone on MM. Complementation was determined by comparing growth of paired isolates with growth of individual isolates. 


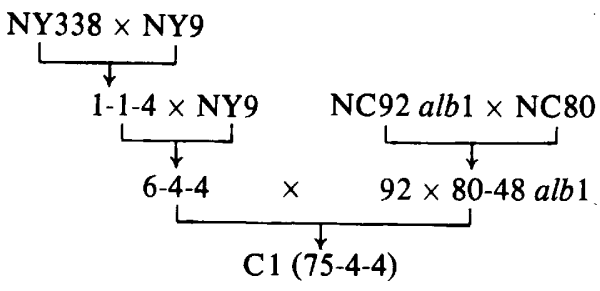

Fig. 1. Derivation of C. heterostrophus isolate $\mathrm{C} 1$.

Sexual fertility. Three agar blocks $(2 \times 2 \times 2 \mathrm{~mm})$ bearing mycelium were taken from the edge of freshly re-isolated, sexually compatible isolates and placed on opposite sides of a naturally senescent, autoclaved corn leaf $(1 \times 4 \mathrm{~cm}$ ) lying flat on the surface of Sach's medium (Luttrell, 1958). The crosses were incubated in the dark for $18 \mathrm{~d}$ at $25^{\circ} \mathrm{C}$. For analysis of fertility, the pseudothecia from each cross were counted after the $18 \mathrm{~d}$ incubation, six pseudothecia being squashed under a coverslip in cotton blue/lactophenol and observed microscopically for determination of the percentage of asci with eight ascospores.

Genetic analysis. Under a dissecting microscope, individual pseudothecia were crushed with jeweller's forceps on a block $(30 \times 30 \times 8 \mathrm{~mm})$ of CM containing $5 \%(w / v)$ agar. Rosettes of asci were dissected freehand with a fine-tipped wire needle. Asci were ruptured by gently pressing them with the needle against the agar, releasing the ascospores, which were separated from each other on the agar surface. Small pieces of agar, each bearing a single ascospore, were isolated in individual tubes or on plates of CM. The resulting colonies were subcultured to appropriate media in order to score for segregation of mutant traits. In crosses that produced eight-spored asci, the analysis of tetrads (which are not ordered) was possible. In crosses that produced no eight-spored asci, segregation of traits was examined among randomly isolated spores.

Storage of stock cultures. All fungal isolates were preserved as silica gel cultures, prepared and stored by slight modifications of the procedures of Perkins $(1962,1977)$. Some isolates were also stored in infected leaves, obtained as described previously (Yoder \& Gracen, 1975). To achieve infection by poorly conidiating strains, mycelium from a $2 \mathrm{~d}$ liquid $\mathrm{CM}$ shake culture was fragmented for $15 \mathrm{~s}$ in a blender in sterile water and dropped into the whorls of corn seedlings ( $14 \mathrm{~d}$ old) which then were held in a mist chamber for $48 \mathrm{~h}$. After $7 \mathrm{~d}$ in a growth chamber, leaves with lesions were removed aseptically, placed between sterile sheets of blotting paper for 1-4 weeks, and stored at $5{ }^{\circ} \mathrm{C}$ in manila envelopes within moisture-proof boxes containing desiccant. Cultures were retrieved by plating a surface-sterilized $(1.2 \%, \mathrm{w} / \mathrm{v}$ sodium hypochlorite for $15 \mathrm{~s})$ leaf piece or silica gel crystals on CM. For long-term storage, the silica gel method was more convenient and preserved the fungus more reliably than the infected-leaf method.

\section{RESULTS}

\section{Culturing}

Several minimal agar media were compared with our standard complex medium, PJA, by measuring their ability to support growth and conidiation of $C$. heterostrophus. The fungus performed poorly on most of the media tested (Table 1). Therefore, minimal (MM) and complete (CM) media specifically suited for $C$. heterostrophus were developed. Since the fungus grew relatively fast on modified Sach's medium (Table 1), the salts in that medium were selected as the basis of a new medium. Concentrations of each ion in modified Sach's medium were varied, while keeping the remaining ions and culture conditions constant and determining the response of $C$. heterostrophus. The effect of nitrogen source and concentration was tested by using $\mathrm{NH}_{4} \mathrm{NO}_{3}, \mathrm{Ca}\left(\mathrm{NO}_{3}\right)_{2} \cdot 4 \mathrm{H}_{2} \mathrm{O}$, and $\mathrm{NH}_{4} \mathrm{Cl}$ each at $0.01,0 \cdot 1$, $0.5,1.0$, and $2.0 \mathrm{~g} \mathrm{l}^{-1}$. The phosphate source was tested by comparing $\mathrm{CaH}_{2}\left(\mathrm{PO}_{4}\right)_{2} . \mathrm{H}_{2} \mathrm{O}$, $\mathrm{KH}_{2} \mathrm{PO}_{4}$, and $\mathrm{K}_{2} \mathrm{HPO}_{4}$ each at $0 \cdot 1,0.2,0 \cdot 5$, or $1.0 \mathrm{~g} \mathrm{l}^{-1} \cdot \mathrm{MgSO}_{4} \cdot 7 \mathrm{H}_{2} \mathrm{O}$ was tested at 0.05 , $0.01,0.25,0.5$, and $1.0 \mathrm{~g} \mathrm{l}^{-1}$. $\mathrm{NaCl}$ was tested at $0.05,0 \cdot 1,0.2$, and $0.25 \mathrm{~g} \mathrm{l}^{-1}$. Results showed that $C$. heterostrophus was supported best by the following salts and concentrations $\left(\mathrm{g} \mathrm{l}^{-1}\right): \mathrm{Ca}\left(\mathrm{NO}_{3}\right)_{2} \cdot 4 \mathrm{H}_{2} \mathrm{O}(1 \cdot 0), \mathrm{KH}_{2} \mathrm{PO}_{4}(0 \cdot 2), \mathrm{MgSO}_{4} .7 \mathrm{H}_{2} \mathrm{O}(0 \cdot 25)$, and $\mathrm{NaCl}(0 \cdot 15)$. To store salts as $100 \times$ stocks, the $\mathrm{Ca}\left(\mathrm{NO}_{3}\right)_{2} \cdot 4 \mathrm{H}_{2} \mathrm{O}$ solution was prepared separately to avoid precipitation. Carbon sources for MM (sucrose, glucose, xylose and starch) were each tested 
Table 1. Effect of varying culture medium on radial growth and conidiation of C. heterostrophus isolate $C 2$

The mean diameter of colonies on PJA at $7 \mathrm{~d}$ was $72 \mathrm{~mm}$; there were $2.3 \times 10^{6}$ conidia per $10 \mathrm{~cm}$ Petri dish after $10 \mathrm{~d}$. Incubation was at $23^{\circ} \mathrm{C}$ with a $16 \mathrm{~h}$ photoperiod. The results are expressed as percentages of the values on PJA.

Medium Reference

PJA
Neurospora
Vogel's
Fries'
Rhizoctonia
Harding's
C. sativus
Sach's
C. heterostrophus
minimal (MM)
C. heterostrophus
complete (CM)

Yoder \& Gracen (1975)

Beadle \& Tatum (1945)

Vogel (1964)

Luke \& Wheeler (1955)

VanEtten \& Bateman (1971)

Harding (1975)

Tinline et al. (1960)

Luttrell (1958)

This report

This report

$\begin{array}{cc}\text { Radial growth* } & \text { Conidiation } \\ 100 & 100 \\ 36 & <0 \cdot 1 \\ 31 & 4 \\ 33 & <0 \cdot 1 \\ 48 & 18 \\ 70 & 121 \\ 70 & 1 \\ 91 & 42 \\ 91 & 218 \\ 78 & 257\end{array}$

* Each value is the mean of eight plates.

+ Supplemented with 15 g glucose $\mathrm{l}^{-1}$.

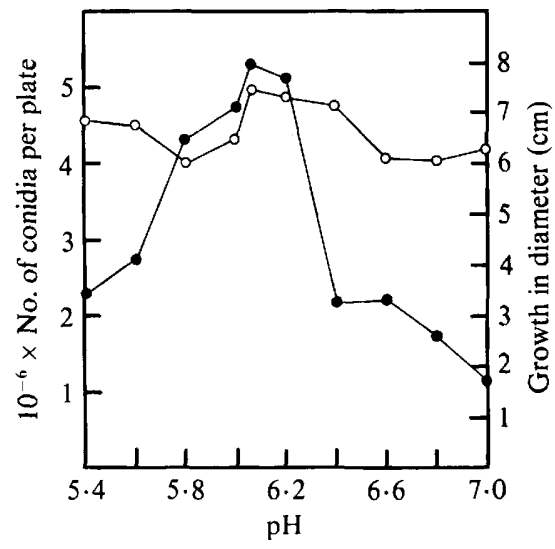

Fig. 2

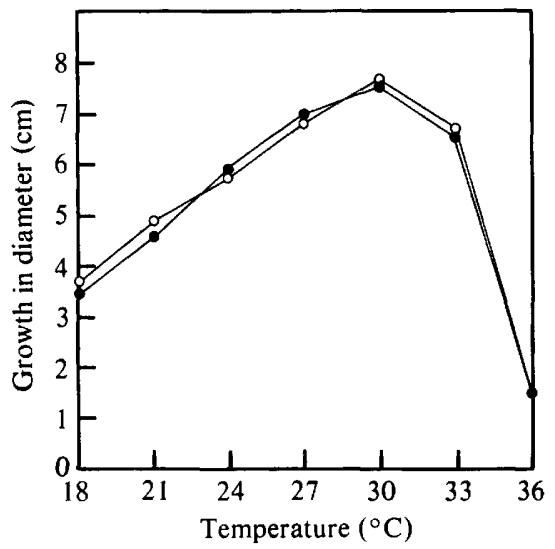

Fig. 3

Fig. 2. Effect of varying $\mathrm{pH}$ on growth (O), and conidiation (O) of C. heterostrophus isolate $\mathrm{C} 2$ incubation on complete medium (CM) for $7 \mathrm{~d}$ at $23^{\circ} \mathrm{C}(16 \mathrm{~h}$ photoperiod).

Fig. 3. Effect of varying temperature on radial growth of near-isogenic $C$. heterostrophus isolates $\mathrm{C} 2$ tox-(O), and $\mathrm{C} 4$ tox $+(\mathrm{O})$, after $5 \mathrm{~d}$ on PJA. Initial inoculum was $3 \mathrm{~mm}$ in diameter. Each value is the mean of 10 plates. Similar results were obtained using CM.

at $1,5,10,15$, and $20 \mathrm{~g} \mathrm{l}^{-1}$. Glucose at $10 \mathrm{~g}^{-1}$ supported the best radial growth and conidiation. To determine the supplements for MM that were required for CM, yeast extract and casein hydrolysate (half acid-hydrolysed and half enzymically hydrolysed) were added to $\mathrm{MM}$ at $0.3,1.0$, and $3.0 \mathrm{~g}^{-1}$ in all possible combinations. Growth and conidiation were the same on all combinations ( $1 \mathrm{~g}$ of each per litre was adopted for CM). Growth on CM was the same from $\mathrm{pH} 5.4$ to 7.0 but conidiation was best at $\mathrm{pH} 6.0$ (Fig. 2). The final $\mathrm{pH}$ of $\mathrm{MM}$ and $\mathrm{CM}$ after autoclaving was 6.05. Both $\mathrm{MM}$ and $\mathrm{CM}$ supported a growth rate almost as 
Table 2. Effect of light on conidiation of C. heterostrophus isolate C2

Cultures were grown for $10 \mathrm{~d}$ at $23^{\circ} \mathrm{C}$ on $\mathrm{CM}$ in darkness, under white light (Sylvania 'cool white') or under near-UV light $(300-400 \mathrm{~nm}$, Syvania $375 \mathrm{BL})$. Conidia were suspended in water plus Tween 20 and counted. Each value is the mean of five plates.

\begin{tabular}{|c|c|c|c|c|}
\hline \multirow[b]{3}{*}{$\begin{array}{l}\text { Culture } \\
\text { medium }\end{array}$} & \multicolumn{4}{|c|}{$10^{-6} \times$ No. of conidia per plate } \\
\hline & \multicolumn{4}{|c|}{ Light conditions: } \\
\hline & $\begin{array}{l}\text { White } \\
(24 \mathrm{~h})\end{array}$ & $\begin{array}{l}\text { White } \\
(16 \mathrm{~h})\end{array}$ & $\begin{array}{l}\mathrm{UV} \\
(16 \mathrm{~h})\end{array}$ & Darkness \\
\hline PJA & $1 \cdot 2$ & $2 \cdot 3$ & 2.8 & 0.2 \\
\hline $\mathrm{CM}$ & $2 \cdot 0$ & $3 \cdot 0$ & 7.2 & 0.2 \\
\hline MM & 1.5 & $3 \cdot 5$ & $6 \cdot 1$ & 0.1 \\
\hline
\end{tabular}

Table 3. Conidiation of near-isogenic C. heterostrophus race $T($ tox +$)$ and race $O($ to -$)$ isolates

Isolates C3 (tox-) and $\mathrm{C} 4($ tox +$)$ were grown for $7 \mathrm{~d}$ at $23^{\circ} \mathrm{C}$ on $\mathrm{CM}$ or PJA under a $16 \mathrm{~h}$ photoperiod. Conidia were suspended in water plus Tween 20 and counted with a haemocytometer. Each value is the mean of 10 plates.

$\begin{array}{ccc}\text { Isolate } & \text { PJA } & \text { CM } \\ \text { C3 (tox }-) & 4 \cdot 19^{\mathrm{a}} & 8.95^{\mathrm{b}} \\ \mathrm{C} 4(\text { to } x+) & 3 \cdot 75^{\mathrm{a}} & 7.66^{\mathrm{b}}\end{array}$

* Numbers followed by the same letter are not significantly different $(P=0.05)$.

high as on PJA and both media induced conidiation substantially greater than that on PJA (Tables 1 and 2).

To restrict colony diameters for efficient plate counts, glucose concentration was reduced to $2 \mathrm{~g}^{-1}$ in $\mathrm{MM}$ and $0.5 \mathrm{~g}^{-1}$ in CM, and sorbose $\left(20 \mathrm{~g}^{-1}\right)$ added (Tatum et al., 1949). This caused $95 \%$ restriction of radial growth but had no effect on the germination rates of plated conidia. Triton X-100 (VanEtten \& Kolmark, 1977) at 0.01-0.04\%, limited colony size but also inhibited germination of plated conidia by $50 \%$.

Mycelial growth increased with increasing temperature up to $33^{\circ} \mathrm{C}$, and then fell sharply (Fig. 3). However, conidiation was best at temperatures below $25^{\circ} \mathrm{C}$. Light stimulated conidiation (Table 2); wavelengths in the long-UV range (300-400 nm, Sylvania F15T8 375 BL 'Blacklite') were more effective than visible light (Sylvania 'Coolwhite'). Isolates bearing alb1 had the same radial growth rate on CM and MM, but produced only $30 \%$ as many conidia as wild type.

Near-isogenic race $\mathrm{T}($ to $x+)$ and race $\mathrm{O}($ tox -$)$ isolates grew and conidiated at the same rate on PJA at all temperatures tested (Table 3, Fig. 3). On CM at $24{ }^{\circ} \mathrm{C}$ and $27{ }^{\circ} \mathrm{C}$, the growth of tox- was $6-10 \%$ less than that of tox+, all other rates being the same as those obtained on PJA. Both isolates were re-checked after the experiments to determine that race identification was correct.

\section{Mutagenesis}

Auxotrophs were not recovered among the survivors of preliminary experiments with NTG, UV or nitrous acid mutagenesis, even after enrichment procedures were performed. The reasons for this are unknown. Morphological mutants were induced by the foregoing mutagens. All auxotrophs obtained to date resulted from EMS treatments causing 97-99.9\% death. 
Table 4. Efficacies of enrichment procedures after mutagenesis of $C$. heterostrophus conidia with EMS

Enrichment procedures (described in Methods) were compared for the number of auxotrophic mutants among survivors and the ability of the resultant auxotrophs to cross with a wild-type isolate.

$\begin{array}{lcc}\text { Enrichment } & \begin{array}{c}\text { Percentage of } \\ \text { auxotrophs }\end{array} & \begin{array}{c}\text { Percentage } \\ \text { fertile }\end{array} \\ \text { None } & 0.05 & 30 \\ \text { Nystatin } & 5 \cdot 0 & 0 \\ \text { Cycloheximide } & 5 \cdot 0 & 0 \\ \text { Filtration } & 0 \cdot 1 & 30 \\ \text { Filtration with sorbose } & 2 \cdot 0 & 30 \\ \text { Inositol-less death } & 0 & -\end{array}$

Table 5. Mutants of C. heterostrophus

Class

Description

No. of mutants

Auxotrophic
met
ade
ins
arg
ile
his
lys
rib
nit
unk
Colour*
alb1
alb2
red
grey
Morphological*
col
slo
spg
sas
bdd
rpy
Drug resistant $\dagger$
eth
cyh
to

Requires methionine

Requires adenosine

Requires inositol

Requires arginine

Requires isoleucine

Requires histidine

Requires lysine

Requires riboflavin

Nitrate non-utilizer

Requirements unknown

3
4
3
2
1
1
1
1
3
16

White colony, white pseudothecia 1

Off-white colony, black pseudothecia

Stains red in staling cultures

Dark grey colony, black pseudothecia

Colonial growth 3

Slow growth 3

Spongy growth

Slow and sparse growth

Beaded hyphae

Ropey growth

Resistant to ethionine

Resistant to cycloheximide

* Phenotypes determined on CM.

$\dagger$ Ethionine and cycloheximide were included at 200 and $100 \mu \mathrm{g} \mathrm{ml}^{-1}$, respectively; ethionine tests were done on MM.

\section{Enrichment for auxotrophs}

The antibiotic procedure with either nystatin or cycloheximide resulted in 100-fold enrichment of auxotrophs (Table 4), but all were infertile when mated with wild-type. Filtration enrichment caused a twofold increase in the recovery of auxotrophs, and addition of sorbose to the filtration medium increased recovery 40 -fold. About $30 \%$ of auxotrophs obtained by filtration enrichment were fertile (Table 4). The inositol-less death procedure was tested in reconstruction experiments with double auxotrophs (ins 1;ade 1 and ins 1;met 3 ). In all cases the double auxotroph died at a faster rate than the ins 1 mutant alone. When mutagenized conidia of ins 1 were subjected to the procedure, no additional auxotrophs were recovered. 
Table 6. Allelism at eth (ethionine-resistant) loci in C. heterostrophus

Mutants were crossed among each other and progenies were screened on minimal medium containing $200 \mu \mathrm{g}$ ethionine $\mathrm{ml}^{-1} ;$ eth 1 and $e t h 4$ were infertile with each other.

$\begin{array}{lc}\text { Cross } & \begin{array}{c}\text { Progeny ratio } \\ \text { (sensitive }: \text { resistant) }\end{array} \\ \text { eth } 3 \times \text { eth } 1 & 16: 7 \\ \text { eth3 } \times \text { eth2 } & 0: 33 \\ \text { eth } 3 \times \text { eth3 } & 0: 22 \\ \text { eth } 3 \times \text { eth } 4 & 7: 34 \\ \text { eth } 3 \times \text { eth5 } & 0: 42 \\ \text { eth } 1 \times \text { eth } 2 & 13: 17 \\ \text { eth } 1 \times \text { eth5 } & 1: 6\end{array}$

\section{Characterization of mutants}

There have been 42 defined mutants obtained so far, as well as 16 whose nutritional requirements were not determined (Table 5). Most of the auxotrophs did not grow at all on minimal medium. A few were 'leaky', but were easily scored in segregating progenies. All fertile mutants were shown by genetic analysis to contain single gene mutations. When placed on corn plants, all mutants (except for the severe morphological types) produced lesions, although some of the auxotrophs were weakly virulent unless the inoculum was supplemented with the required nutrient. Mutants resistant to cycloheximide caused apparently normal lesions on corn plants in the presence or absence of cycloheximide. Wild-type fungus did not cause lesions on cycloheximide-treated plants (W. E. Fry, unpublished).

Within each class of mutant (Table 5), several independently arising mutants showed the same phenotype. Attempts were made to distinguish between mutations at the same locus and mutations at different loci. Genetic analysis of five of the six mutants resistant to ethionine showed that eth 2 , eth 3 and eth 5 were alleles and that eth 1 and eth 4 were at a different locus or loci (Table 6). Three auxotrophs requiring methionine were infertile when mated with each other; however, complementation analysis showed that when met 1 and met 3 , or met 2 and met 3 were paired on minimal medium, growth occurred, but when met 1 and met 2 were paired there was no growth. Thus, met 1 and met 2 appear to be alleles at the same locus, and met 3 represents a separate locus. Three of the four adenosine-requiring mutants were analysed by complementation; they appeared to be mutants at three loci. This result was confirmed by sexual genetic analysis. Progenies from crosses of ade $1 \times$ ade 2 and ade $1 \times$ ade 3 showed two-gene segregation, indicating that the ade 1 locus is distinct from ade 2 or ade3. Crosses between ade 2 and ade 3 were infertile. Despite indications of several loci, only adenosine or methionine supported the growth of the ade or met auxotrophs, respectively, and the precursors were ineffective, perhaps because they were not taken up. Allelism of other independently arising mutants with the same phenotype (ins, arg, ile, nit, col, slo) could not be determined because isolates did not complement and were not fertile with each other.

The two albino mutants (Table 5) showed two-gene segregation when mated with each other; $a l b 2$ produced black pseudothecia as the female parent whereas $a l b 1$ produced white pseudothecia. Use of $a l b 1$ in matings with $a l b+$ permits reciprocal crosses and facilitates detection of female sterile isolates.

\section{Media for sexual reproduction}

An attempt was made to develop a defined medium that supported sexual reproduction as well as the senescent corn leaf procedure (see Methods). Sach's medium (Luttrell, 1958) was modified by making the following additions or substitutions: (1) $\mathrm{Ca}\left(\mathrm{NO}_{3}\right)_{2} \cdot 4 \mathrm{H}_{2} \mathrm{O}(0 \cdot 5,1 \cdot 0$, $5.0,10$ and $\left.15 \mathrm{~g} \mathrm{l}^{-1}\right)$; (2) nitrogen source $\left(1.0 \mathrm{~g} \mathrm{l}^{-1}\right.$ of either $\mathrm{Ca}\left(\mathrm{NO}_{3}\right)_{2} \cdot 4 \mathrm{H}_{2} \mathrm{O}$, urea, casein hydrolysate, $\mathrm{NH}_{4} \mathrm{NO}_{3},\left(\mathrm{NH}_{4}\right)_{2} \mathrm{SO}_{4}$, asparagine or glutamine as a replacement for the 


\section{Table 7. Breeding for sexual fertility of C. heterostrophus}

Progenies were scored for fertility as described in Methods. The most fertile individuals were used in the subsequent generation. The five field isolates were previously determined to be relatively fertile by mating with isolates $\mathrm{C} 2$ and $\mathrm{C} 3$.

\begin{tabular}{clc} 
Cross & \multicolumn{1}{c}{ Parents and their origin } & $\begin{array}{c}\text { Percentage of asci } \\
\text { with eight spores }\end{array}$ \\
1 & C1 $1 \times \mathrm{HmZ}$ (Kentucky) & 25 \\
2 & Progeny of cross 1 $\times \mathrm{HmB2}$ (New York) & 25 \\
3 & Progeny of cross $2 \times$ PAG17657L1 (New York) & 30 \\
4 & Progeny of cross $3 \times$ F-481 (Italy) & 30 \\
5 & Progeny of cross $4 \times 19679$ (Australia) & 40
\end{tabular}

$\mathrm{Ca}\left(\mathrm{NO}_{3}\right)_{2} \cdot 4 \mathrm{H}_{2} \mathrm{O}$; calcium concentration was kept constant by the addition of the appropriate amount of $\left.\mathrm{CaCl}_{2} .2 \mathrm{H}_{2} \mathrm{O}\right)$; (3) carbon source $\left(0,0.01,0.1\right.$ or $1.0 \mathrm{~g} \mathrm{l}^{-1}$ of either cellobiose, mannose, trehalose, maltose, inulin, glucose, sucrose, fructose, lactose, potato starch, soluble starch, xylose, ribose, cellulose, or mannitol); (4) thiamin $\left(0.01,0.05\right.$ and $\left.0.1 \mathrm{mg} \mathrm{l}^{-1}\right) ;(5)$

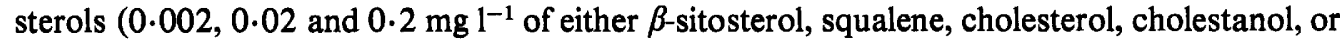
ergosterol); (6) $\mathrm{ZnSO}_{4} \cdot \mathrm{H}_{2} \mathrm{O}\left(10,30,50,80\right.$ and $\left.100 \mathrm{mg} \mathrm{l}^{-1}\right)$; (7) methionine $(0 \cdot 5,1 \cdot 0,1 \cdot 5$ and $\left.2.0 \mathrm{gl}^{-1}\right)$; (8) yeast extract $\left(0.001,0.05\right.$ and $\left.0.1 \mathrm{gl}^{-1}\right)$; (9) vitamins were added individually or combined at the concentrations used by Holliday (1974); (10) micronutrients (Sanderson \& Srb, 1965) were added at $0.5,1.0,5.0$ and $10 \mathrm{ml} \mathrm{l}^{-1}$, and (11) $\mathrm{pH}$ was adjusted to $5,6,7,8$ or 9 . Each variation of the medium was tested using corn leaf, filter paper (Whatman no. 1), or dialysis tubing as a physical support. In addition, the following supporting agents were compared with a corn leaf on the basal Sach's medium: aluminum foil (Alcoa), nylon netting (60 $\mu \mathrm{m}$ mesh), plastic film ('Stretch-and-Seal' $)$, glass beads $(0.25-0.30 \mathrm{~mm}$ diameter), glass coverslips, Millipore filters $(0.2 \mu \mathrm{m}$ pore size), sea sand, Teflon tape, Sephadex beads (G-25), and glass wool. All evaluations of media and supports were done by mating isolates $\mathrm{C} 2$ and $\mathrm{C} 3$.

None of the 373 modified media tested increased sexual fertility beyond that achieved with the standard corn leaf procedure. Most caused a decrease in fertility. Addition of trehalose or casein hydrolysate to Sach's medium and replacement of the corn leaf with dialysis tubing resulted in production of asci and ascospores but fewer than with the corn leaf procedure. In combination, trehalose and casein hydrolysate caused infertility. Dialysis tubing or filter paper alone, as replacements for the corn lead, promoted profuse production of pseudothecia; however, few asci and ascospores developed. None of the other supports tested allowed the formation of pseudothecia.

\section{Breeding for fertility}

Using the standard mating procedure, crosses between field isolates of opposite mating type may be completely infertile, or they may produce ascospores. Most of the fertile matings yield low numbers of ascospores and complete tetrads (eight ascospores) are rarely found. To improve the level of fertility, two breeding programmes were performed. The first approach involved backcrossing each of the following isolates for at least six generations, to isolate $\mathrm{Cl}$ (Fig. 1): alb1, alb2, and tox-. Isolates $\mathrm{C} 2$ and $\mathrm{C} 3$ resulted from this breeding programme. The second approach was based on the use of germplasm from diverse geographical locations. Field isolates from continental USA, Mexico, Australia, Hawaii, Nigeria, Italy and Japan were tested for fertility with isolates C2 and C3. The most fertile germplasm was then combined with that derived from the first breeding programme (Table 7). Both programmes resulted in isolates that consistently produced $40-50 \%$ of the asci with complete tetrads. Using these strains, Guzman et al. (1982) found that under rigidly controlled conditions up to $80 \%$ of the asci had tetrads while the rest had $4-6$ spores. 


\section{DISCUSSION}

We have developed laboratory protocols that are suitable for manipulation and genetic analysis of $C$. heterostrophus by conventional microbiological methods. Culture media can be efficiently prepared from concentrated stocks; environmental conditions can be varied for optimum growth of mycelium or for conidiation; mutants can be induced, selected, and characterized; and conventional genetic analyses can be performed using laboratory strains that have been bred and selected for increased fertility.

It was necessary to develop new media for $C$. heterostrophus because those reported by others (Harding, 1975; Trainor \& Martinson, 1978) either were undefined or sustained sub-optimal performance of $C$. heterostrophus. The complete and minimal media developed for $C$. heterostrophus also supported good growth and conidiation of $C$. carbonum, $C$. sativum and $C$. victoriae, but they were not satisfactory for our isolates of $C$. miyabeanus or Setosphaeria turcica.

The frequency of auxotrophs recovered from mutagenized populations of $C$. heterostrophus was relatively low. A contributing factor may have been the multinucleate nature of the conidia (approx. 10 nuclei per cell and 5-9 cells per conidium) that were used for mutagenesis. The presence of many nuclei per propagule necessitates mutagenesis conditions that result in a high percentage of killed conidia, so that survivors are likely to contain only one viable nucleus. Extraneous mutations that might occur as a result of severe mutagenesis can be removed by back-crossing. There are other reports that mutants can be recovered from fungi that have multinucleate conidia (Greaney \& Machacek, 1933; Tinline et al., 1960; Beadle \& Tatum, 1945; Tinline, 1961; Papa, 1969; Sanchez et al., 1975).

Near-isogenic isolates of tox $+($ race $T)$ and tox- (race O) were essentially identical in culture under all conditions tested. Previous reports of differences in colour, conidiation and temperature optima were based on use of field isolates of race $\mathrm{T}$ and race $\mathrm{O}$ (Fukuki \& Aragaki, 1972; Warren et al., 1977; Locci \& Locci, 1972; Hooker et al., 1970). Such differences may have been due to uncontrolled genetic heterogeneity at loci not associated with race. However, Leonard (1977) reduced non-essential differences between the two races by twelve generations of back-crossing and found that race $\mathrm{T}$ grew $6 \%$ more than race $\mathrm{O}$ in $10 \mathrm{~d}$ at $28^{\circ} \mathrm{C}$ and $32^{\circ} \mathrm{C}$ on PDA (there were no differences at other temperatures). We found that race $\mathrm{T}$ grew $6 \%$ more than the near-isogenic race $\mathrm{O}$ in $7 \mathrm{~d}$ at $21^{\circ} \mathrm{C}$ and $24^{\circ} \mathrm{C}$ (but not at other temperatures) on CM. There were no differences at any temperature on PJA (Fig. 3). It is clear from these results that there is little or no difference in in vitro performance between the races, and that race $O$ is no better adapted to grow at high temperatures than race $T$.

The protocols presented here can be modified slightly to obtain mycelium for production of large numbers of protoplasts $\left.\left[10^{8} \text { (g fungus) }\right)^{-1}\right]$, to regenerate protoplasts at high frequency, and to study heterokaryosis. In addition, high molecular weight DNA can be prepared in milligram quantities (Sweigard \& Kindle, unpublished). Thus, the basic tools necessary for studying the molecular mechanisms of pathogenesis using the techniques of molecular biology are available and are currently being employed for this purpose in our laboratory.

This work was supported in part by grant no. 75002 from the Rockefeller Foundation and by grant no. 78-59-2361-9-1-004-1 from the Competitive Research Grants Office of the Science and Education Administration/United States Department of Agriculture. We thank Drs K. J. Leonard, C. W. Boothroyd, J. L. Alcorn, R. Locci, and H. Wheeler for supplying fungal cultures.

\section{REFERENCES}

Applegate, P. J., Nelson, R. E. \& Metzenberg, R. L. (1978). Mutant enrichment by filtration concentration: a variation for the selection of tempera- ture-conditional heterocaryons. Neurospora Newsletter 25, 17.

BASSEL, J. \& OGRYdziaK, D. M. (1979). Genetics of 
Saccharomycopsis lipolytica, with emphasis on genetics of hydrocarbon utilization. In Genetics of Industrial Microorganisms, pp. 160-165. Edited by O. K. Sebek \& A. I. Laskin. Washington, D.C.: American Society for Microbiology.

Beadle, G. W. \& TAtum, E. L. (1945). Neurospora II. Methods of producing and detecting mutations concerned with nutritional requirements. American Journal of Botany 32, 678-686.

FukukI, K. A. \& ARAGAKI, M. (1972). Temperature and light effects on cultural differences between races $\mathrm{T}$ and $\mathrm{O}$ of Helminthosporium maydis. Phytopathology 62, 676-678.

Garber, R. C., Fry, W. E., Yoder, O. C. \& Apple, A. E. (1981). Southern corn leaf blight: a plant disease system for definitive epidemiological research. Phytopathology 71, 875 (abstract).

Greaney, F. J. \& MACHACEK, J. E. (1933). The production of a white fertile saltant of Helminthoporium sativum by means of ultra-violet radiation. Phytopathology 23, 379-383.

Guzman, D., Garber, R. C. \& Yoder, O. C. (1982). Cytology of meiosis I and chromosome number of Cochliobolus heterostrophus (Ascomycetes). Canadian Journal of Botany (in the Press).

Harding, H. (1975). Effect of $\mathrm{pH}$ and sucrose concentration on conidium size and septation in four Bipolaris species. Canadian Journal of Botany 53, 1457-1464.

Holliday, R. (1956). A new method for the identification of biochemical mutants of microorganisms. Nature, London 178, 987.

Holliday, R. (1974). Ustilago maydis. In Handbook of Genetics, vol. 1, pp. 575-595. Edited by R. C. King. New York: Plenum Press.

HoOKeR, A. L., SMITH, D. R., LIM, S. M. \& MusSon, M. D. (1970). Physiological races of Helminthosporium maydis and disease resistance. Plant Disease Reporter 54, 1109-1110.

LEONARD, K. J. (1977). Virulence, temperature optima, and competitive abilities of isolines of races $T$ and $O$ of Bipolaris maydis. Phytopathology 67, 12731279.

LESTER, H. E. \& Gross, S. R. (1959). Efficient method for selection of auxotrophic mutants of Neurospora. Science 129, 572.

Lindegren, C. C. \& Lindegren, G. (1944). Sporulation in Saccharomyces cerevisiae. Botanical Gazette 105, 304-316.

Lindegren, C. C., BeANFIELd, V. \& Barber, R. (1939). Increasing the fertility of Neurospora by selective inbreeding. Botanical Gazette 100, 592599.

Locc1, R. \& Locc1, J. R. (1972). Possible means of differentiating on malt agar between physiological races $\mathrm{T}$ and $\mathrm{O}$ of Helminthosporium maydis. Rivista di patologia vegetale 8, 231-238.

Luke, H. H. \& WheEler, H. E. (1955). Toxin production by Helminthosporium victoriae. Phytopathology 45, 453-458.

LutTrell, E. S. (1958). The perfect stage of Helminthosporium turcicum. Phytopathology 48, 281-287.

PAPA, K. E. (1969). Auxotrophic mutants of Cochliobolus carbonum. Mycologia 61, 799-807.
Payne, G. A. \& Yoder, O. C. (1978). Effect of the nuclear genome of corn on sensitivity to Helminthosporium maydis race $\mathrm{T}$-toxin and on susceptibility to H. maydis race T. Phytopathology 68, 331-337.

Perkins, D. D. (1962). Preservation of Neurospora stock cultures with anhydrous silica gel. Canadian Journal of Microbiology 8, 591-594.

Perkins, D. D. (1977). Details for preparing silica gel stocks. Neurospora Newsletter 24, 16-17.

SANCHEZ, L. E., LeARY, J. V. \& ENDo, R. M. (1975). Chemical mutagenesis of Fusarium oxysporum f.sp. lycopersici: non-selected changes in pathogenicity of auxotrophic isolates. Journal of General Microbiology 87, 326-332.

SANDERSON, K. E. \& SRB, A. M. (1965). Heterokaryosis and parasexuality in the fungus Ascochyta imperfecta. American Journal of Botany 52, 72-81.

SNow, R. (1966). An enrichment method for auxotrophic yeast mutants using the antibiotic 'Nystatin'. Nature, London 211, 206-207.

SRB, A. M. (1974). Mutation and selection in fungi. In Haploids in Higher Plants: Advances and Potential, pp. 289-308. Edited by K. J. Kasha. Guelph, Ontario, Canada: Office of Continuing Education, University of Guelph.

TATUM, E. L., BarratT, R. W. \& Cutter, V. M., JR (1949). Chemical induction of colonial paramorphs in Neurospora and Syncephalastrum. Science 109, 509-511.

Tinline, R. D. (1961). Cochliobolus sativus IV. Drug resistant, color, and nutritionally exacting mutants. Canadian Journal of Botany 39, 1695-1704.

Tinline, R. D., Stauffer, J. F. \& Dickson, J. G. (1960). Cochliobolus sativus. III. Effect of ultraviolet radiation. Canadian Journal of Botany 38, 275-282.

Trainor, M. J. \& MARTINSON, C. A. (1978). Nutrition during spore production and the inoculum potential of Helminthosporium maydis race T. Phytopathology 68, 1049-1053.

VANETTEN, H. D. \& BATEMAN, D. F. (1971). Studies on the mode of action of the phytoalexin phaseollin. Phytopathology 61, 1363-1372.

VANETten, H. D. \& KolmaRk, H. G. (1977). Modifying the growth habit of the filamentous fungus Fusarium solani to facilitate replica plating procedures. Canadian Journal of Botany 55, 848851.

VoGEL, H. J. (1964). Distribution of lysine pathways among fungi: evolutionary implications. American Naturalist 98, 435-446.

W ARren, H. L., Jones, A., JR \& Huber, D. M. (1977). Morphological and physiological differences between Bipolaris maydis races $\mathrm{O}$ and T. Mycologia 69, 773-782.

Woodward, V. W., De Zeeuw, J. R. \& SRB, A. M. (1954). The separation and isolation of particular biochemical mutants of Neurospora by differential germination of conidia, followed by filtration and selective plating. Proceedings of the National Academy of Sciences of the United States of America 40, 192-200.

YODER, O. C. (1976). Evaluation of the role of Helminthosporium maydis race $\mathrm{T}$ toxin in southern corn leaf blight. In Biochemistry and Cytology of 
Plant Parasite Interaction, pp. 16-24. Edited by K. YODER, O. C. \& GRACEN, V. E. (1975). Segregation of Tomiyama, J. M. Daly, I. Uritani, H. Oku \& S. pathogenicity types and host-specific toxin proOuchi. New York: Elsevier.

YODER, O. C. (1979). Experience with the ApplegateNelson-Metzenberg method of mutant enrichment in high sorbose medium. Neurospora Newsletter 26, duction in progenies of crosses between races $T$ and $\mathrm{O}$ of Helminthosporium maydis (Cochliobolus 23-24. heterostrophus). Phytopathology 65, 273-276. 